times good upon insanity and epilepsy which are associated with severe dysmenorrhœa, or occur periodically at the menstrual epochs; but when the insanity is constant, although aggravated at the monthly periods, removal of the appendages is of no benefit. Hystero-epilepsy is seldom permanently cured, and prolonged after-treatment is generally necessary. Local pain is often not relieved. 'Certain cases of neurasthenia; associated with dysmenorrhœe, or structural changes of the ovaries, are cured; nevertheless no such case should be subjected to the operation without beforehand having the benefit of prolonged and patient treatment. It is unjustifiable to remove the ovaries and tubes in cases of neurasthenia, hysteria, etc., when these organs are healthy. A. F.

\title{
A CASE OF HYSTERICAL ANURIA WITH URINARY EMESIS.
}

Dr. Fabio Vitali; of Bologna, in the "Bulletino delle Scienze Medicle" for November, 1891, reports in brief a case of hysteria, in which there existed urinary vomiting with anuria from end of March to the end of July. In commenting upon the case the author asserts that hysterical anuria does not produce uræmic poisoning, because in these cases urea is present in infinitesmal quantities. The quantity of urea in the vomited matter did not surpass five grammes daily, neither was there an increase of urea in the circulation. He combats the theory that hysterical anuria is due to a spasmodic contracture of the ureters, but explains it as an inhibitory process of the nervous and secretory centres, similar to the pathogenesis of hysterical polyuria.

W. C. K.

\section{SUB-DURAL HEMORRHAGE.}

In the "Am. Jour. of the Med. Sciences," February, I 892, Bremer and Carson have a very instructive paper, in which the following interesting case is cited: A healthy man, aged twenty-one, while intoxicated, fell between the joists of a new building. There were no evidences of any serious trouble until a week later, when he suddenly became unconscious and fell in the street. This attack was of only short duration, but soon after he became aphasic. No signs of any external injury to the head could be seen. Although understanding what was said, he could not repeat words spoken to him. He compre- 
hended perfectly what he read. There was obliteration of the right naso-labial fold, and on showing his teeth the left fold became very marked and the left angle of the mouth was drawn to the left. During an effort to whistle there was puffing of right cheek. The tongue deviated to the right. While unable to write words, he could put down figures with comparative ease. A diagnosis was made of blood-clot (probably extra-dural) pressing principally on the foot of third frontal (Broca's) convolution and the foot of the second frontal (probable centre for vomiting), impinging also on the face and tongue centres of left hemisphere. Symptoms of rapidly increasing brain pressure having set in, he was trephined an inch and a quarter behind the external angular process and the same distance above the base line. On opening the dura, a stream of dark blood forced itself through the superficial layer of the clot and spattered those standing two and three feet away. After removal of the clot he began immediately to improve, and in nine days from operation was discharged cured.

A. F.

\section{THE SIGNIFICANCE OF OCULAR SYMPTOMS IN BRAIN DISEASE.}

C. A. Oliver, M.D. (Am. Jour. of the Med. Sciences, February, I 892) divides the special symptom-groupings into two kinds-the sensory and the motor-each of which expresses itself in two ways-the irritative tnd the degenerative. With proper and extended study of these four series, which he understands to be expressive of both sensory and motor changes in an apparatus extending through so vast an intra-cranial area, and with careful reasoning and accurate noting of the many changes constantly arising in the numerous combinations of their associated conditions and actions, much may be expected. In conclusion, he broadly asserts that when any part of this special sensory channel is irritated or inflamed, there may be hyperæsthesia, as shown by symptoms of increase of functional activity, such as phosphenes, etc., associated at times with coarse subjective changes in the fundus of the eye; but if it be lowered in vitality by any cause, anæsthesia will be present, as shown by decrease of physiological action, such as diminishing and actual loss of macular and circum-macular vision, which frequently may be connected with visible degenerative lesions in the ocular background. If there 